\title{
Vibrational Properties of Tellurium Tetrachloride
}

\author{
Enrique J. Baran \\ Centro de Química Inorgánica (CEQUINOR/CONICET. UNLP). Facultad de Ciencias Exactas. \\ Universidad Nacional de La Plata, C. Correo 962, 1900-La Plata, Argentina \\ Reprint requests to Prof. E.J.B.: Fax: (054) 0221 4259485: E-mail: baran@quimica.unlp.edu.ar
}

Z. Naturforsch. 60a, $408-410$ (2005): received March 2, 2005

\begin{abstract}
On the basis of the most recently reported spectroscopic data on vibrational modes in $\mathrm{TeCl}_{4}$ and structural parameters of $\mathrm{TeCl}_{4}$. an estimation of its main force constants complemented with the calculation of mean amplitudes of vibration in a wide temperature range have been performed. Also thermodynamic functions for the ideal gaseous state of the molecule calculated, using the statistical mechanics approach.
\end{abstract}

Key words: $\mathrm{TeCl}_{4}$ : Force Constants: Mean Amplitudes of Vibration: Thermodynamic Functions.

The gas phase infrared and Raman spectra as well as the corresponding spectra in $\mathrm{Ar}$ and $\mathrm{N}_{2}$ matrixes of $\mathrm{TeCl}_{4}$ have been reported more than thirty years ago by Beattie et al. [1]. However, the vibrational description remained incomplete since only seven of the nine fundamental vibrations can be found in these studies. The vibrational assignment of this molecule was only completed recently, performing a new measurement of the gas phase IR spectrum. complemented by an ab initio molecular orbital calculation at the MP2 level [2].

Using the spectroscopic and structural data reported in this study, we have now performed the calculation of the most important vibrational properties and ideal gas phase thermodynamic functions of this molecule.

The molecular geometry of $\mathrm{TeCl}_{4}$ is consistent with VSEPR theory [3]. It can formally be derived from the $\mathrm{sp}^{3} \mathrm{~d}$ hybridization of the central atom. with the lone pair occupying one of the equatorial positions of the trigonal pyramidal arrangement. The computed geometrical parameters are the following: $\mathrm{Te}-\mathrm{Cl}_{\mathrm{eq}}=$ $2.13 \AA$ : $\mathrm{Te}-\mathrm{Cl}_{\mathrm{ax}}=2.441 \AA ; \mathrm{Cl}_{\mathrm{eq}}-\mathrm{Te}-\mathrm{Cl}_{\mathrm{eq}}=100.2^{\circ}$ and $\mathrm{Cl}_{\mathrm{ax}}-\mathrm{Te}-\mathrm{Cl}_{\mathrm{ax}}=176.6^{\circ}$ [2]. The large space requirement of the electronic lone pair is shown by the $\mathrm{Cl}_{\mathrm{eq}}{ }^{-}$ $\mathrm{Te}-\mathrm{Cl}_{\mathrm{eq}}$ angle less than $120^{\circ}$ and by the tilt of the axial chlorines towards the equatorial ones, as well as by the longer axial bonds. Notwithstanding, and as discussed below, an alternative approach, based on a well-known empirical semi-ionic model, may be more adequate for a better description of the Te-Cl bonds.

In order to attain a wider insight into the bond characteristics we have made an approximate calculation of the principal force constants. using the valence force field proposed by Siebert for $\mathrm{Y}_{2} \mathrm{XZ}_{2}$ molecules of $C_{2 v}$ symmetry [4], but neglecting coupling effects between species of the same symmetry. The results are shown in Table 1. In this table. $f$ refers to Te-Cl bonds. $f^{\prime}$ to bond/bond interactions, $f_{\alpha}$ to $\mathrm{Cl}_{\mathrm{eq}}-\mathrm{Te}-\mathrm{Cl}_{\mathrm{eq}}$ and $f_{\beta}$ to $\mathrm{Cl}_{\mathrm{ax}}-\mathrm{Te}-\mathrm{Cl}_{\mathrm{ax}}$ angles.

As it can be seen from the data presented in Table 1 . the $\mathrm{Te}-\mathrm{Cl}$ equatorial bonds are appreciable stronger than the axial ones, in agreement with the estimated greater length of these last bonds. The value estimated for the $\mathrm{Te}-\mathrm{Cl}_{\mathrm{eq}}$ bond compares reasonably well with that calculated for the $\mathrm{Te}-\mathrm{Cl}$ bonds in the pyramidal $\mathrm{TeCl}_{3}{ }^{+}$cation $(2.27 \mathrm{mdyn} / \mathrm{A})$ [5].

Using these calculated force constants for the two types of $\mathrm{Te}-\mathrm{Cl}$ bonds it is possible to make a rough estimate of their bond orders, using the empirical method of Siebert [5,6]. This calculation shows that the equatorial bonds present a bond order of about of 1.2 . whereas the axial bonds are weaker with a bond order of only 0.8 , pointing also to substantial differences in the bond strength and characteristics of both bond types.

These results are in agreement with the semi-ionic three center-four electron ( $3 \mathrm{c}-4 \mathrm{e}$ ) bond model $[3,7,8]$. In the frame of this model, the equatorial $\mathrm{Cl}$ atoms are bound by regularly localized two center-two electron $(2 c-2 e)$ bonds via $\mathrm{sp}^{2}$ hybridized orbitals on the central atom. with the lone pair on the remaining lobe of this hybrid orbital. Then, the axial $\mathrm{F}$ atoms must be in $3 \mathrm{c}-4 \mathrm{e}$ bonds, using the remaining $\mathrm{p}$ orbital of tellurium, and generating more ionic and weaker bonds [9. 10]. 
Table 1. Approximate force constants (in $\mathrm{mdyn} / \overline{\mathrm{A}}$ ) for $\mathrm{TeCl}_{4}$.

\begin{tabular}{cccccc}
\hline$f\left(\mathrm{Te}-\mathrm{Cl}_{\mathrm{eq}}\right)$ & $f\left(\mathrm{Te}-\mathrm{Cl}_{\mathrm{ax}}\right)$ & $f^{\prime}\left(\mathrm{Te}_{\mathrm{C}}-\mathrm{Cl}_{\mathrm{eq}}\right)$ & $f^{\prime}\left(\mathrm{Te}-\mathrm{Cl}_{\mathrm{ax}}\right)$ & $f_{\alpha}$ & $f_{\beta}$ \\
\hline 2.39 & 1.48 & 0.30 & 0.0 & 0.20 & 0.04 \\
\hline
\end{tabular}

Table 2. Calculated mean amplitudes of vibration (in $\bar{A}$ ) for $\mathrm{TeCl}_{4}$.

\begin{tabular}{lccccc}
\hline$T(\mathrm{~K})$ & $u_{\mathrm{Te}-\mathrm{Cl}(\mathrm{eq})}$ & $u_{\mathrm{Te}-\mathrm{Cl}(\mathrm{ax})}$ & $u_{\mathrm{Cl} \ldots \mathrm{Cl}(\mathrm{eq})}$ & $u_{\mathrm{Cl} \ldots \mathrm{Cl}(\mathrm{ax})}$ & $u_{\mathrm{Cl}(\mathrm{eq}) \ldots \mathrm{Cl}(\mathrm{ax})}$ \\
\hline \multicolumn{1}{c}{0.0400} & 0.0448 & 0.066 & 0.057 & 0.079 \\
100 & 0.0401 & 0.0454 & 0.071 & 0.058 & 0.089 \\
200 & 0.0427 & 0.0502 & 0.086 & 0.065 & 0.111 \\
298.16 & 0.0470 & 0.0567 & 0.101 & 0.074 & 0.132 \\
300 & 0.0471 & 0.0568 & 0.101 & 0.074 & 0.132 \\
400 & 0.0519 & 0.0636 & 0.115 & 0.083 & 0.151 \\
500 & 0.0566 & 0.0699 & 0.128 & 0.092 & 0.168 \\
600 & 0.0612 & 0.0759 & 0.140 & 0.100 & 0.183 \\
700 & 0.0656 & 0.0816 & 0.150 & 0.107 & 0.198 \\
800 & 0.0697 & 0.0869 & 0.161 & 0.114 & 0.211 \\
900 & 0.0737 & 0.0919 & 0.170 & 0.121 & 0.224 \\
1000 & 0.0774 & 0.0967 & 0.179 & 0.127 & 0.236 \\
\hline
\end{tabular}

Table 3. Statistical thermodynamic functions (in cal/deg mol) of $\mathrm{TeCl}_{4}$

\begin{tabular}{lcccr}
\hline$T(\mathrm{~K})$ & $C_{p}$ & $\left(H^{0}-H_{0}{ }^{0}\right) / T$ & $-\left(G^{0}-H_{0}{ }^{0}\right) / T$ & $S^{0}$ \\
\hline 100 & 16.86 & 11.81 & 56.83 & 68.65 \\
200 & 22.07 & 15.86 & 66.38 & 84.24 \\
298.16 & 23.90 & 18.25 & 73.20 & 91.45 \\
300 & 23.92 & 18.29 & 73.31 & 91.60 \\
400 & 24.70 & 19.81 & 78.79 & 98.60 \\
500 & 25.09 & 20.83 & 83.33 & 104.16 \\
600 & 25.31 & 21.56 & 87.20 & 108.76 \\
700 & 25.45 & 22.11 & 90.56 & 112.67 \\
800 & 25.54 & 22.53 & 93.54 & 116.08 \\
900 & 25.60 & 22.87 & 96.22 & 119.09 \\
1000 & 25.64 & 23.14 & 98.64 & 121.79 \\
1100 & 25.68 & 23.37 & 100.86 & 124.23 \\
1200 & 25.70 & 23.57 & 102.90 & 126.47 \\
1300 & 25.72 & 23.73 & 104.79 & 128.53 \\
1400 & 25.74 & 23.87 & 106.56 & 130.43 \\
1500 & 25.75 & 24.00 & 108.21 & 132.21 \\
\hline
\end{tabular}

For a wider characterization of the telluriumchlorine bonds, we have also calculated the mean amplitudes of the vibrations of $\mathrm{TeCl}_{4}$. These calculations were performed with the method of characteristic vibrations of Müller et al. [11] (cf. also [12, 13]). The obtained results. in the temperature range between 0 and $1000 \mathrm{~K}$. are shown in Table 2.

[1] I. R. Beattie. O. Bizri. H.E. Blayden. S. B. Brumbach, A. Bukovszky, T.R. Gilson, R. Moss, and B.A. Phillips, J. Chem. Soc. 1974, 1747.

[2] A. Kovács and R. J. M. Konings, J. Mol. Struct. 410/411, 407 (1997).

[3] J.E. Huheey, E.A. Keiter, and R. L. Keiter. Inorganic
The results of these calculations are in excellent agreement with the calculated force constants and with the discussed bond characteristics, as the equatorial bonds present lower mean amplitude values than the axial ones, in the full temperature range. On the other hand, and in agreement with the commented similar value of the force constants, the Te- $\mathrm{Cl}$ bond in the $\mathrm{TeCl}_{3}$ cation presents an identical mean amplitude value $(0.047 \AA$ A at $298 \mathrm{~K})$ [12] as for the $\mathrm{Te}-\mathrm{Cl}_{\text {eq }}$ bonds.

A comparison with the octahedral $\mathrm{TeCl}_{6}{ }^{2-}$ anion. also containing $\mathrm{Te}$ (IV), is interesting too. The force constant of $1.20 \mathrm{mdyn} / \AA$ calculated for the Te-Cl bonds in this case [14] immediately shows weaker bonds than in $\mathrm{TeCl}_{4}$. Consequently, the mean amplitudes of vibration of $\mathrm{TeCl}_{6}{ }^{2}$ are also relatively higher (0.0484 $\mathrm{A}$ at $0 \mathrm{~K}$ and $0.0649 \mathrm{~A}$ at $298 \mathrm{~K}$ [14]) than those of both types of Te-Cl bonds in $\mathrm{TeCl}_{4}$.

Finally. we have calculated the thermodynamic functions in a wide temperature range, for the ideal gaseous state (unit fugacity) using the rigid rotator, harmonic oscillator approximation $[15,16]$. The moments of inertia were calculated with the MOLDRAW program [17]. The symmetry number is 2 .

The results. specific heat $\left(C_{p}\right)$, reduced enthalpy $\left[\left(H^{0}-H_{0}{ }^{0}\right) / T\right]$, reduced free enthalpy $\left[\left(G^{0}-H_{0}{ }^{0}\right) T\right]$ and entropy $\left(S^{0}\right)$, in the temperature range between 100 and $1200 \mathrm{~K}$, are presented in Table 3.

To conclude, these calculations provide a wider insight into the vibrational properties of $\mathrm{TeCl}_{4}$, an interesting representative of the rather uncommon $\mathrm{XY}_{4}$ type molecules, containing a central heavy metal atom. and possessing $C_{2 v}$ symmetry.

\section{Acknowledgements}

This work was supported by the Universidad Nacional de La Plata (Project 11/X339) and the "Consejo Nacional de Investigaciones Científicas y Técnicas de la República Argentina". The author is a member of the Research Career of this organism.

Chemistry. Principles of Structure and Reactivity. $4^{\text {th }}$ Ed., Harper-Collins, New York 1993.

[4] H. Siebert, Z. Anorg. Allg. Chem. 275, 210 (1954).

[5] H. Siebert. Anwendungen der Schwingungsspektroskopie in der Anorganischen Chemie. Springer, Berlin 1966. 
[6] A. Fadini and F.M. Schnepel, Schwingunsspektroskopie. Methoden. Anwendungen, Thieme, Stuttgart 1985.

[7] G. C. Pimentel J. Chem. Phys. 10, 446 (1951).

[8] R. E. Rundle. J. Am. Chem. Soc. 85, 112 (1963).

[9] O. J. Curnow, J. Chem. Educ. 75, 910 (1998).

[10] E. J. Baran. Z. Naturforsch. 56a. 333 (2001).

[11] A. Müller. C. J. Peacock. H. Schulze, and U. Heidborn. J. Mol. Struct. 3, 252 (1969).

[12] A. Müller. E. J. Baran. and K. H. Schmidt. Characteristic Mean Amplitudes of Vibration; in: Molecular Struc- tures and Vibrations (Ed. S. J. Cyvin), Elsevier, Amsterdam 1972.

[13] E. J. Baran. An. Asoc. Quím. Argent. 61. 141 (1973).

[14] M.N. Avasti and M. L. Mehta, Z. Naturforsch. 25a, $566(1970)$.

[15] K. S. Pitzer, Quantum Chemistry, Prentice Hall, New Jersey 1953.

[16] G. Allen and H. O. Pritchard. Statistical Mechanics and Spectroscopy, Butterworths, London 1974.

[17] P. Ugliengo. D. Viterbo, and G. Chiari. Z. Kristallogr. 207, 9 (1993). 